\title{
Marie-Claude Hubert, Le Nouveau Théâtre (1950-1968)
}

\section{Paola Perazzolo}

\section{(2) OpenEdition}

\section{Journals}

\section{Edizione digitale}

URL: http://journals.openedition.org/studifrancesi/8068

DOI: 10.4000/studifrancesi.8068

ISSN: 2427-5856

\section{Editore}

Rosenberg \& Sellier

\section{Edizione cartacea}

Data di pubblicazione: 1 juillet 2009

Paginazione: 438

ISSN: 0039-2944

\section{Notizia bibliografica digitale}

Paola Perazzolo, «Marie-Claude Hubert, Le Nouveau Théâtre (1950-1968)», Studi Francesi [Online], 158

(LIII | II) | 2009, online dal 30 novembre 2015, consultato il 08 janvier 2021. URL: http://

journals.openedition.org/studifrancesi/8068 ; DOI: https://doi.org/10.4000/studifrancesi.8068

\section{Questo documento è stato generato automaticamente il 8 janvier 2021.}

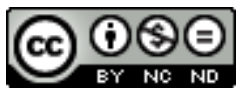

Studi Francesi è distribuita con Licenza Creative Commons Attribuzione - Non commerciale - Non opere derivate 4.0 Internazionale. 


\title{
Marie-Claude Hubert, Le Nouveau Théâtre (1950-1968)
}

\author{
Paola Perazzolo
}

\section{NOTIZIA}

MARIE-CLAUDE HUBERT, Le Nouveau Théâtre (1950-1968), Paris, Champion, 2008

(«Dictionnaires \& Références», 17), pp. 413.

1 Facente parte della serie diretta da Ch. Mazouer sulla storia del teatro francese, questo volume rievoca la produzione di anni fondamentali come quelli tra il 1950 e il 1968. Dopo un breve capitolo introduttivo (État des lieux) riguardante mutamenti e avvenimenti sociali e artistici - l'avvio della decentralizzazione, la creazione del T.N.P., la scoperta di Brecht, l'inizio del fenomeno dei registi créateurs, le influenze straniere alla base delle esperienze collettive successive -, Hubert si concentra sulla presentazione degli autori, iniziando da drammaturghi (Les aînés) già in attività tra le due guerre che continuano, con maggiore o minore fortuna, a proporre pièces dalla struttura tradizionale: gli autori del théâtre de boulevard, ma anche grandi quali Anouilh, Sartre, Camus, Montherlant, Cocteau, Giroudoux. Nome di transizione appare invece Claudel: le sue audacie sceniche minano le fondamenta della drammaturgia francese e influenzano artisti come Audiberti, Vauthier, Schehadé (Les poètes de la scène), il cui teatro lirico non solo dà spazio all'immaginario, all'esuberanza barocca, alla fantasia, ma magnifica la parola e le sue qualità incantatorie. Nel frattempo, nei teatri della Rive Gauche, nuovi creatori (Grotesque et onirique e Les romanciers au théâtre) portano a compimento la rivoluzione drammaturgica del secolo. Ionesco e in parte Ghelderode scoperto trent'anni dopo - reinterpretano la tradizione del circo e del music hall e compongono anti-pièces e farces tragiques che introducono lo spettatore in universi destabilizzanti e irreali in cui il comico e il tragico convivono e si scontrano per significare la difficoltà della parola e l'assurdità del quotidiano; Tardieu evidenzia le incongruità del linguaggio; Vian e Arrabal distruggono a colpi di ironia ferocissima o immagini surreali pregiudizi e aberrazioni sociali. La rappresentazione delle défaillances 
del linguaggio costituisce un tratto comune anche ai testi di Beckett, Duras, Pinget e Sarraute, dove la trasposizione scenica di procedimenti narrativi utilizzati in precedenza spiega un intertitolo per altri aspetti forse poco adatto. Oggetto privilegiato di analisi è ancora la parola, disgregata e poi progressivamente interiorizzata nelle opere di Beckett, o disturbante se espressione della "sotto-conversazione" in Sarraute. A questa produzione, non priva di messaggi politici ma nemmeno dichiaratamente impegnata, si affianca in questo periodo l'opera di autori come Adamov, Gatti, Vinaver, Genet, che denunciano il sistema alienante del capitalismo, gli scandali e le violenze della guerra e della colonizzazione, o che evocano dall'interno il dramma della decolonizzazione - Césaire, Yacine e Depestre (Le théâtre politique).

2 Sulla base di una ricca documentazione - scritti teorici, testimonianze di autori, attori e registi, recensioni - volta a rendere la complessità della creazione, della rappresentazione e della ricezione dell'opera, M.-C. Hubert, nota specialista di estetica e letteratura teatrale del periodo, traccia un panorama preciso dei molteplici orientamenti di questi anni, offrendo uno strumento importante per la conoscenza di due decadi giustamente considerate come «tout aussi brillantes pour le théâtre français que la période classique» (p. 371). 